\title{
To the Jubilee of Professor Alexander Priezzhev
}

On April 3, 2017 Professor Alexander Priezzhev, the Head of the Laboratory of Laser Biomedical Photonics of the Physics Department and International Laser Centre of M.V. Lomonosov Moscow State University (MSU), a recognized expert in biophysics, actively working in the field of biophotonics, biomedical optics, and nanobiophotonics, celebrated his jubilee 70 -th birthday.

Alexander Priezzhev was born in the family of a specialist in hydraulic work building, well-known in the USSR, who worked in the Glavsevmorput' (Nothern Sea Root Headquarters) system for many years. His activities included the construction of ports at the Arctic Ocean shore (Igarka, Dudinka, etc.) and the work in Vietnam.

As early as studying at school, Alexander was fascinated by physics. He entered the evening school at the MSU, where the lectures were delivered by Russian outstanding physicists, B.B. Bukhovtsev, V.D. Krivchenkov, V.G. Zubov, and M.A. Leontovich. When he was a second-year University student, he began research work at the chair, headed by Prof. Sergey P. Strelkov, which at that time had an unofficial name of cybernetics chair. After the third year of study, he began working with Victor I. Shmalgausen who was a supervisor of his graduate work and postgraduate study. The graduate work was devoted to the solution of fundamental and applied problems of optimal control. The research in this field was continued in the postgraduate study, and in 1975 Alexander defended his $\mathrm{PhD}$ thesis. After the PhD defence, under the general supervision of Prof. Sergey A. Akhmanov - new head of the chair, Alexander carried out a substantial cycle of research work on mathematical modelling and experimental studies of intracellular hydrodynamics in cooperation with Prof. Yuri M. Romanovsky, the head of the Mathematical Biophysics group, and the colleagues from the Institute of Theoretical and Experimental Biophysics of RAS in Pushchino. It is worth noting that his studies on laser Doppler anemometry in application to biophysics were largely affected by the communication with Bronyus S. Rinkevichyus, presently a professor in the National Research University "MPEI", one of the pioneers of the method in Russia, with whom Alexander continues to collaborate up to now. The first results of laser measurements of the protoplasm motion velocity in living cells were published in 1978 in the "Biophysics" and "Quantum Electronics" journals. Later not only the self-oscillatory but also the autowave motions in cells were studies theoretically and experimentally. In particular, the existence of a standing-wave mode in the autowave process of amoeboid motility of Physarum mixomycete plasmodium was found. These results corresponded to the international level, and, in particular, drew the attention of Professor Karl-Ernst WohlfartBotterman from the University of Bonn, a distinguished expert in cell biophysics.

In 1988, the first laser Doppler microscope for the examination of non-muscular biological motility was developed and rapidly published in the MSU Department of Physics Preprint. This microscope was displayed at the exhibition of scientific developments of the Council for Mutual Economic Assistance and awarded an honorary diploma.

In 1989-1990 on the suggestion of Sergey A. Akhmanov and in collaboration with Vyacheslav M. Gordienko, Alexander began working on the construction of Doppler lidars for remote measurement of wind velocity in the atmosphere. The lidars based on the solid-state Nd:YAG laser, the continuous-wave $\mathrm{CO}_{2}$ laser and the pulsed TEA- $\mathrm{CO}_{2}$ laser were made, using which he 
performed atmospheric wind velocity measurements from the high-rise meteorological tower in the town of Obninsk and from the marine platform in the Black Sea.

Yuri M. Romanovsky and Alexander have developed and starting from 1980 for many years delivered a new lecture course "Laser and computer experiment in modern biophysics." In 1982 Yuri L. Klimontovich, an outstanding expert in chaos and turbulence theory and the author of wellknown books on synergetics, invited Alexander to develop and teach jointly the course "Turbulence" completed with the experimental methods of the turbulence studies.

The most fruitful research and science-organising activity of Alexander began in the late 1980s early 1990s and was related to the solution of problems in the field of laser biomedical diagnostics and the initiation and development of active international cooperation. As early as 1986 initiated by Sergey A. Akhmanov, the first international conference on Lasers Application in Life Sciences (LALS) in Prague, Czechoslovakia was held, and Alexander was one of its major organisers. All subsequent LALS conferences were held in more than ten countries under his active participation as one of the key organisers. A few last conferences were initiated by him and successfully held due to his great energy and efforts, namely, the conferences in Taipei (2008), Oulu (2010), Ulm (2014), and Shenzhen (2016), largely due to his fruitful international links.

In these years, the in-depth studies carried out by Professor Priezzhev in the fields of optics and biophysics of blood, its rheological properties, the interaction of blood cells with laser radiation, the fundamental problems of elastic and quasielastic scattering of light by biological cells and tissues made him one of the world leaders in biomedical optics. In the same years, the fruitful collaboration with Saratov State University (SSU) began. He actively took part in the implementation of largescale research, education and publishing projects together with the Chair of Optics, later renamed as the Chair of Optics and Biophotonics of SSU. It would be adequate to mention the book by A.V. Priezzhev, V.V. Tuchin and L.P. Shubochkin [1], which was the first monograph in the USSR and one of the first ones in the world, as well as the first monograph in the world Handbook of Optical Biomedical Diagnostics (2002). The latter has become a reference book in many laboratories of the world, recently its two-volume second edition [2] was issued, and earlier it was published as a twovolume collective textbook in Russian $[3,4]$.

Alexander is a brilliant lecturer and successful scientist, regularly invited for delivering lectures in the leading world centres on optical biophysics and for taking part in the programme and organising committees of numerous leading international conferences. During the period from 1983 to 2017 he was awarded nearly 70 scientific and educational grants for carrying out research and delivering lectures in the leading world universities.

Alexander is a member of SPIE-the International Society for Optics and Photonics. From the very beginning of SPIE activity in Russia he directed much of his efforts to international activity within the frameworks of this society. He is one of the founders of world-wide known SPIE symposium on biomedical optics BiOS in the USA and its European analogue EurBiOS. Thanks to Alexander's activity and help up to ca. 100 Russian scientists took part in the European symposium annually.

In the same years, starting from 1996 to the present day Alexander was the soul and ideological inspirer of the annual international school and conference on optics, laser physics, and biophotonics (Saratov Fall Meeting) http://sfm.eventry.org/2016/. 


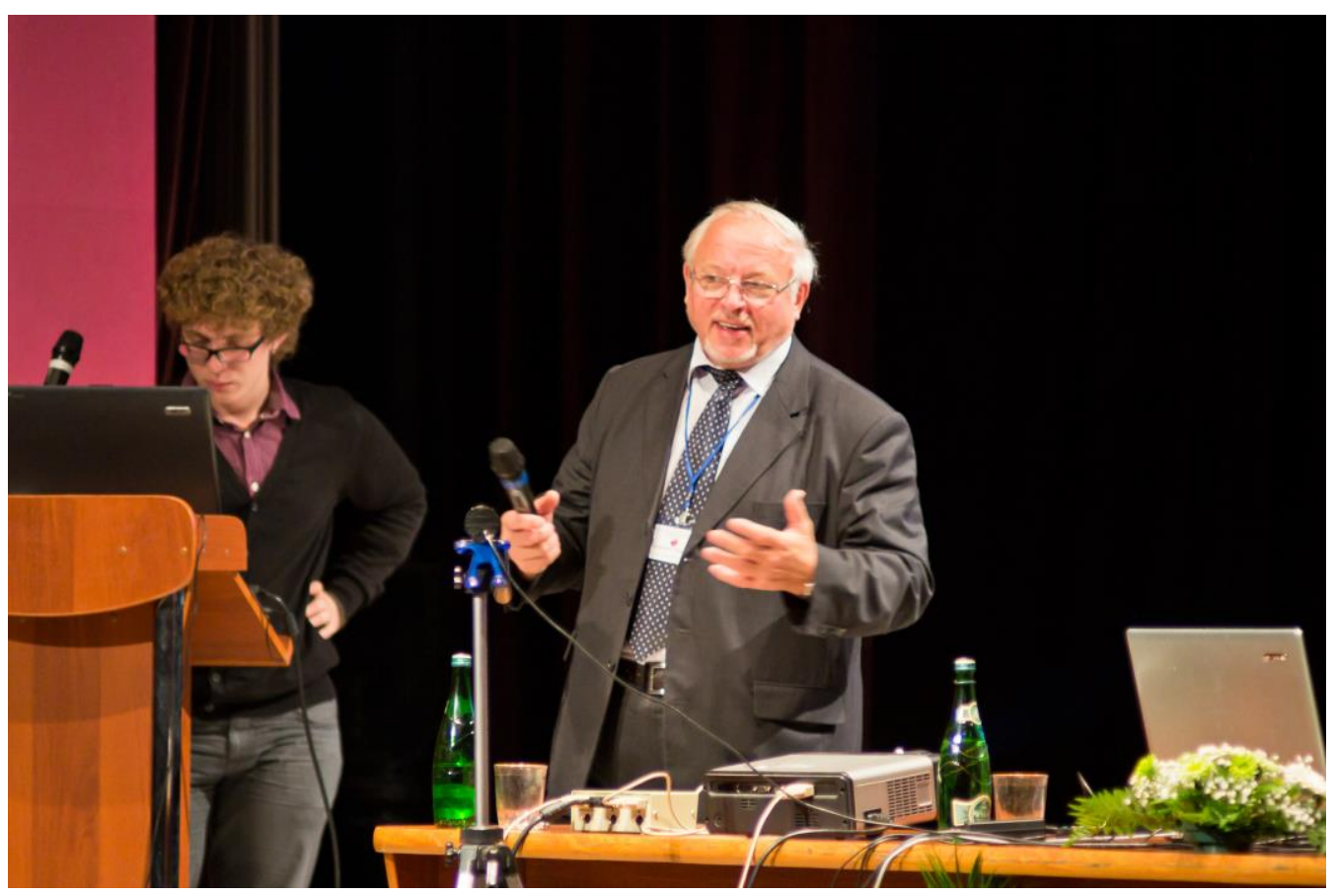

Saratov Fall Meeting-2016

It is difficult to list all conferences, in the organisation of which Alexander took part. We would like to mention only one more of them, the annual international conference on Advanced Laser Technologies (ALT), where for many years he is responsible for biophotonics topic. In particular, quite recently, in September 2016, a successful conference ALT'16 comprising a large number of interesting talks was held in Galway (Ireland), and the next one is currently being prepared to be held in Pusan (Republic of Korea) in September 2017. At present the preparation of the special issue of Journal Biomedical Optics, devoted to the conference ALT-2016, is about to be finished [5].

The high activity and responsibility of Professor Priezzhev in training world-class young specialists and his ability to organise perfect and mutually beneficial international cooperation is worth special attention. We present only three examples here. The first example is the long-lasting collaboration with Professor Juergen Lademann from the Charité University Clinic of Humboldt University (Germany). The second remarkable example is the fruitful cooperation during 15 years with Professor Risto Myllylä from the University of Oulu (Finland), where two of his former students are working now. One of the important results of the mutual research is the well-known monograph [6]. And the third example is the successful and also long-time collaboration with Professor ChiaLiang Cheng from the National Dong Hwa University, Hualien, Taiwan.

The research and science-organising activity of Alexander is highly appreciated in Russia and abroad. For example, from 1997 he fills the position of Adjunct-Professor at School of Biomedical Engineering, Science, and Health Systems of the Drexel University (USA). On the eve of the jubilee, Alexander was awarded the MSU First Prise for the scientific publications in the frames of the MSU Programme of Development (2016). This award characterises well the scientific 
achievements, wide scope and prospects of the scientific field, developed by Alexander at present time, it is sufficient just to read the titles of some papers for which this prise was awarded [7-18].

The total number of $19 \mathrm{PhD}$ theses were successfully defended under the supervision of Professor Priezzhev. The main field of study in these works was biomedicine and biophotonics. Under his supervision and with his participation multiple national and international research projects in medical physics and biomedical optics were carried out, he published more than 350 papers in refereed journals, books and conference proceedings.

Alexander pays much attention to the important work in the Russian and international journals as a member of editorial boards, invited editor or referee, e.g., in such journals as Quantum Electronics (from 2000), Biomedical Optics (1997-2010); Journal of Laser Medicine (from 1997), Journal of Biomedical Photonics \& Engineering (Russia) (from 2014), Journal of Physics D: Applied Physics (2005) and many others.

We congratulate our dear friend and colleague in mutual research and science-organising projects Alexander Priezzhev with honourable 70th anniversary and wish him new interesting projects, good students and strong health.

Yuri M. Romanovsky, M.V. Lomonosov Moscow State University Valery V. Tuchin, Saratov National Research State University

\section{$\underline{\text { References }}$}

1. A. V. Priezzhev, V. V. Tuchin, and L. P. Shubochkin, Laser Diagnostics in Biology and Medicine, Nauka, Moscow (1989) [in Russian].

2. A. V. Priezzhev, K. Lee, N. N.Firsov, J. Lademann, L. T. Perelman, V. Backman, Yu. P. Sinichkin, N. Kollias, G. I. Zonios, S.R. Utz, V. V. Tuchin, et al., Handbook of Optical Biomedical Diagnostics. Methods, $2^{\text {nd }}$ ed., vol. 2, SPIE Press, Bellingham, WA, USA (2016).

3. V. V. Tuchin, N. G. Khlebtsov, I. L. Maksimova, L. V. Wang, A. N. Yaroslavskaya, A. V. Priezzhev, et al., Optical Biomedical Diagnostics, vol. 1, A Tutorial certified by the Ministry of Education and Science of Russia, Fizmatlit, Moscow (2007) [in Russian].

4. A. V. Priezzhev, N. N. Firsov, J. Lademann, L. T. Perelman, V. Beckman, Yu. P. Sinichkin, N. Kollias, G. Zonios, S. R. Utz, V. V. Tuchin, et al., Optical Biomedical Diagnostics, vol 2, A Tutorial certified by the Ministry of Education and Science of Russia, Fizmatlit, Moscow (2007) [in Russian].

5. M. Leahy, T. Keyes, V. V. Tuchin, and A. V. Priezzhev (Guest Eds.), "Advanced Laser Technologies for Biophotonics,” Special Section, J. Biomed. Opt. 22 (2017) [submitted]. 
6. K.-E. Peiponen, R. Myllyla, and A. V. Priezzhev, Optical Measurement Techniques: Innovations for Industry and the Life Sciences, Springer-Verlag, Berlin-Heidelberg (2009).

7. A. V. Priezzhev, H. Schneckenburger, and V. V. Tuchin, "Special Section Guest Editorial: Laser Applications in Life Sciences,” J. Biomed. Opt. 20, 051001 (2015).

8. E. Shirshin, O. Cherkasova, T. Tikhonova, E. Berlovskaya, A.Priezzhev, and V. Fadeev, "Native fluorescence spectroscopy of blood plasma of rats with experimental diabetes: identifying fingerprints of glucose-related metabolic pathways," J. Biomed. Opt. 20, 051033 (2015)

9. A. S. Svetlakova, N. N. Brandt, A. V. Priezzhev, and A. Yu. Chikishev, "Raman microspectroscopy of nanodiamond-induced structural changes in albumin," J. Biomed. Opt. 20, 047004 (2015).

10. S. Yu. Nikitin, A. E. Lugovtsov, V. D. Ustinov, M. D. Lin, and A. V. Priezzhev, "Study of laser beam scattering by inhomogeneous ensemble of red blood cells in a shear flow," J. Innov. Opt. Health Sci. 8, 1550031 (2015).

11. K. Lee, M. Kinnunen, A. V. Danilina, V. D. Ustinov, S. Shin, I. Meglinski, and A. V. Priezzhev, "Characterization at the individual cell level and in whole blood samples of shear stress preventing red blood cells aggregation,” J. Biomechanics 49, 1021-1026 (2016).

12. K. Lee, A. Priezzhev, S. Shin., Y. Francois, and I. Meglinski, "Characterization of shear stress preventing red blood cells aggregation at the individual cell level: The temperature dependence," Clin. Hemorheol. Microcirc. 64, 853-857 (2016).

13. L.-W. Tsai, Y.-C. Lin, E. Perevedentseva, A. Lugovtsov, A. Priezzhev, and C.-L. Cheng, "Nanodiamonds for medical applications: interaction with blood in vitro and in vivo," Int. J. Mol. Sci. 17, 1111 (2016).

14. S. Yu. Nikitin, V. D. Ustinov, Yu. S. Yurchuk, A. E. Lugovtsov, M. D. Lin, and A. V. Priezzhev, "New diffractometric equations and data processing algorithm for laser ektacytometry of red blood cells," J. Quant. Spectr. Radiat. Trans. 178, 315-324 (2016).

15. K. Lee, M. Kinnunen, M. Khokhlova, E. Lyubin, A. Priezzhev, I. Meglinski, and A. Fedyanin, "Optical tweezers study of red blood cell aggregation and disaggregation in plasma and protein solutions,” J. Biomed. Opt. 21, 035001 (2016).

16. A. Priezzhev, and K. Lee, "Potentialities of laser trapping and manipulation of blood cells in hemorheologic research," Clin. Hemorheol. Microcirc. 64, 587-592 (2016).

17. K. Lee, A. V. Danilina, M. Kinnunen, A. Priezzhev, and I. Meglinski, "Probing the red blood cells aggregating force with optical tweezers," IEEE J. Select. Tops. Quant. Electr. 22, 7000106 (2016).

18. Yu. S. Yurchuk, V. D. Ustinov, S. Yu. Nikitin, and A. V. Priezzhev, "Scattering of a laser beam on a wet blood smear and measurement of red cell size distribution," Quantum Electron. 46(6), 515-520 (2016). 